\title{
MUHAMMAD ALI, UM OUTSIDER NA SOCIEDADE AMERICANA?
}

\author{
MS. FLÁVIO PY MARIANTE NETO \\ Mestre em Ciência do Movimento Humano pela UFRGS (Rio Grande do Sul - Brasil) \\ e-mail: flaviomariante@hotmail.com \\ MS. CARLOS FABRE MIRANDA \\ Mestre em Ciências do Movimento Humano pela UFRGS e Professor da Prefeitura \\ Municipal de Porto Alegre - Secretaria Municipal de Educação (SMED) e \\ Secretaria Municipal de Esportes (SME) (Rio Grande do Sul - Brasil) \\ e-mail: carlosfabremiranda@gmail.com

\section{MS. MAURO MYSKIW} \\ Mestre em Ciência do Movimento Humano pela UFSM, Mestre em \\ Administração pela UFSM e Professor da Universidade Estadual do \\ Oeste do Paraná (UNIOESTE) (Paraná - Brasil) \\ e-mail:mmyskiw@hotmail.com

\section{DR. MARCO PAULO STIGGER} \\ Doutor em Ciências do Desporto pela Universidade do Porto (Portugal) e \\ Professor Associado do Depto. de Educação Física da Universidade \\ Federal do Rio Grande do Sul (Rio Grande do Sul - Brasil) \\ e-mail: stigger@adufrgs.ufrgs.br
}

\begin{abstract}
RESUMO
O estudo analisa a carreira do boxeador Muhammad Ali segundo as formulações sobre as relações de poder em configurações apresentadas por Norbert Elias. O propósito foi compreender como um atleta que foi contra questões tão profundas da sociedade estabelecida obteve sucesso profissional. Tratou-se de um estudo documental, tendo como fonte livros, artigos e reportagens publicadas sobre a trajetória do lutador. Concluiu-se que apesar de Ali ter se posicionado contra padrões estabelecidos de sua época em questões como a religião, o racismo e o patriotismo, a sua habilidade técnica acima da média, o seu poder de autopromoção e a sua capacidade de participar do jogo no contexto configuracional de que fazia parte, Ihe deram condições de sobrevivência no mundo do boxe e conseqüente sucesso profissional.
\end{abstract}

PALAVRAS-CHAVE: Muhammad Ali; boxe; configurações. 
O presente estudo' procura discutir aspectos da carreira do boxeador Cassius Marcellus Clay, conhecido como Muhammad Ali², sob um olhar sociocultural. Nas décadas de 1960 e 1970 a trajetória deste lutador foi bastante marcante no boxe mundial e na sociedade dos Estados Unidos, momento em que as manifestações esportivas tornavam-se mais complexas, por estarem imbricadas com interesses econômicos e simbólicos (MARQUSEE, 2003). Esta trajetória ficou conhecida também no Brasil, através de filmes, livros (biográficos), jornais e revistas, que constituíram um discurso a respeito de como ela esteve implicada pela configuração social daquele contexto e como se dariam as relações de poder que tornaram possível a consolidação do boxeador como um ícone da sociedade americana. Com base nos enunciados a cerca da trajetória do lutador em várias dessas formas de mediação, este trabalho desenvolve uma análise configuracional elisiana, cujas reflexões podem servir para compreender os elementos mais latentes da constituição dessa representação.

O propósito foi fazer um levantamento de como as narrativas a respeito da trajetória de Muhammad Ali articulam dinâmicas do boxe, dos empresários, da mídia, do governo e das religiões. A escolha do estudo sobre essas relações se justifica na medida em que são amplamente referidas nos trabalhos que trataram da carreira do lutador (FLORES, 200 I; WACQUANT, 2002; MUHAMMAD ALI, 200I; O MAIOR DE TODOS, 200 I; ALI, 2003; MARQUSEE, 2003; MAILER, 2004). Por isso, a preocupação em compreender como esses discursos tratam da dinâmica dos relacionamentos entre os agentes no universo do boxe e deste universo com outras dinâmicas sociais da sociedade americana da época.

A preocupação não foi fazer um relato da vida de um atleta e sim, através dos enunciados, realizar uma discussão sociológica a respeito das relações que fizeram de Muhammad Ali (um negro, adepto ao islamismo e desertor da guerra do Vietnã) um campeão de boxe e, por fim, um representante típico-ideal da sociedade americana. Para tanto, buscou-se fundamento na teoria proposta por Elias e Scotson (1994) e foi estabelecida uma análise comparativa em relação à vida de Mozart estudada por Elias (1995). Essas obras direcionam um olhar para a sociedade, diferenciando-a entre estabelecidos e outsiders, dois grupos com características diferentes entre si, mas que possuem relações de dependência e simbiose um com o outro ${ }^{3}$.

I. Seguindo orientações da editoria da RBCE, declaramos: o presente trabalho não contou com apoio financeiro de nenhuma natureza para sua realização; não houve conflitos de interesses para realização do presente estudo.

2. Importante citar os dois nomes do atleta, pois a mudança de nome também foi importante na carreira do lutador, como veremos posteriormente.

3. Essa teoria será discutida com mais profundidade com o decorrer do texto, ficando aqui apenas uma idéia geral para inserir o leitor na discussão. 
Ali foi um atleta de sucesso que obteve três títulos mundiais dos pesos pesados, categoria mais importante do cenário pugilístico (REMINICK, 2000), e essa importância do lutador no cenário do boxe lhe proporcionou condições para operar algumas rupturas com questões estabelecidas na sociedade americana. Ela foi fundamental, por exemplo, na negação do boxeador ao que se refere a alguns estereótipos sociais (como o do bom negro), dentro de uma determinada configuração social que normalmente não lhe seria favorável. Em meio aos interesses dos empresários, da mídia, do governo e da religião a respeito de sua importância simbólica, Ali tomou algumas decisões que, em princípio, prejudicaram sua carreira, face ao rompimento com a sociedade estabelecida, mas que foram importantes para transformá-lo num ícone da sociedade americana.

Por compreendermos que as rupturas ofertam boas condições para identificar e rastrear as relações de uma configuração social, a análise da carreira do lutador foi desenvolvida a partir dos enunciados sobre três delas: as suas relações com as disputas raciais americanas; o seu vínculo com a religião muçulmana; e a sua decisão de não participar da Guerra do Vietnã. A escolha destas rupturas deve-se ao fato de que elas estão presentes em todos os trabalhos que são utilizados como fontes neste estudo. Essa recorrência nos levou a perguntar: como as relações sociais entre agentes do mundo do boxe, das empresas, da mídia, do governo e da religião norteamericana estão implicadas nos discursos sobre o boxeador Muhammad Ali, que foi contra normas sociais estabelecidas por um grupo social dominante e teve, ainda assim, sucesso na sua carreira profissional?

\section{METODOLOGIA}

O levantamento das relações sociais entre os agentes que estão vinculados à carreira de Muhammad Ali foi realizado em livros que retrataram a trajetória e as principais lutas do boxeador, filme e documentários que abordaram sua carreira, artigos e reportagens publicadas em periódicos e jornais com o intuito de apresentar análises/fatos relacionados ao lutador. A seleção desses documentos foi feita, inicialmente, a partir das biografias. $O$ trabalho de Flores (200 I) foi a primeira fonte e, após contato com este autor, outras obras biográficas foram sendo inseridas no estudo (MAILER, 1998; REMINICK, 2000). Na sequência, como fontes, foram incorporadas reportagens do Jornal Zero Hora de Porto Alegre (de grande circulação nacional) que publicou matérias em homenagem aos 50 anos do lutador (ZERO HORA, 1998, 2000a, 2000b, 200c) e, por último, um filme (ALI, 2003) e dois documentários (O MAIOR DE TODOS, 200 I ; MUHAMMAD ALI, 200 I). 0 levantamento de informações de fontes distintas (quanto aos objetivos e interesses) representou um esforço de triangulação em torno dos consensos, para que a análise não estivesse estruturada em um tipo de fonte apenas. 
Em cada uma dessas fontes buscou-se mapear as narrativas sobre as relações sociais entre agentes do mundo do boxe, das empresas, da mídia, do governo norteamericano e das religiões, procurando delinear como elas estiveram implicadas na constituição de uma representação da trajetória de um boxeador negro que tornou-se ícone da sociedade norteamericana. $\bigcirc$ estudo das relações a partir das três rupturas já referidas possibilitou uma análise das configurações sociais que estão presentes nos diferentes discursos a respeito do lutador e que, em boa medida, consubstanciam sua representação social.

A análise operada, portanto, foi desenvolvida a partir dos enunciados que se referem às relações entre diferentes agentes sociais que dão forma ao discurso sobre a carreira de Muhammad Ali. Já, o exercício analítico foi realizado com base em noções teóricas constantes em obras de Elias (1995; 200 I ; 2005), e Elias e Scotson (2000), entre elas, a de configuração, de interdependência, e de estabelecidos e outsiders. Estes conceitos são apresentados no decorrer do trabalho, que está organizado em dois tópicos: o primeiro refere-se a um olhar configuracional do boxe na sociedade americana, a partir das principais relações que são constantemente enunciadas e que se articulam com as ações e lugares dos lutadores negros na sociedade norteamericana; e o segundo trata de descrever as principais relações sociais que estão evidenciadas nas rupturas que caracterizaram o discurso sobre a carreira do lutador e o situa, ora como outsider, ora como estabelecido naquela sociedade.

\section{O BOXE, MUHAMMAD ALI E A SOCIEDADE AMERICANA: UM OLHAR CONFIGURACIONAL}

Conforme retratado nos documentos, o boxe na sociedade americana compreende uma configuração em particular, formada por uma "teia de interdependência ou configurações de muitos tipos, tais como famílias, escolas, cidades, estratos sociais ou estados" (ELIAS, 2005, p. 15). Trata-se de um conceito que serve de "[...] instrumento conceptual que tem em vista afrouxar o constrangimento social de falarmos e pensarmos como se o indivíduo e a sociedade fossem antagônicos e diferentes" (ELIAS, 2005, p |4I).

Por esse ponto de vista, é preciso admitir que a capacidade de se tornar um boxeador de sucesso, pouco tem a ver com sua capacidade física ou genética de aguentar socos ou de uma condição física privilegiada ${ }^{4}$. Não são raras as passagens

4. Sobre isso ver o trabalho de Elias (1995, p. 54), especificamente o capítulo intitulado "O artista no ser humano", no qual o autor argumenta sobre o "dom" de Mozart para a música. Para o autor "o dom especial - ou, como se dizia no tempo de Mozart, o 'gênio' que uma pessoa tem, mas não é - em si mesmo constitui um dos elementos determinantes de seu destino social, e, neste sentido, é um fato social, assim como os dons simples de uma pessoa sem gênio". 
nas obras estudadas que retratam a inculcação do modo de ser boxeador, processo denominado por Elias de "segunda natureza" (ELIAS, 1994, p. 142 e 168). Aguentar as duras rotinas de treinamento e os "castigos" sofridos pelo corpo durante a prática está relacionado com as condições de vida do lutador Muhammad Ali, o que é experimentado em bairros periféricos, sob os olhos atentos dos treinadores, seguranças, familiares, amigos, conselheiros e dos empresários (O MAIOR DE TODOS, 200 I ; MUHAMMAD ALI, 200I).

Nesse contexto social emerge o boxeador Classius Marcellus Clay, de uma família de classe média baixa de Louisville, Kentucky, Estados Unidos. Como lutador amador teve 130 vitórias, cujo ápice foi a medalha de outro nos jogos Olímpicos de Roma (1 960). Logo seguiu o caminho natural dos boxeadores norteamericanos e se profissionalizou, em vista da possibilidade de ganhar dinheiro com a prática deste esporte. Ele chamava a atenção por sua técnica apurada, por seu estilo diferente (um "bailarino"), sua inteligência nos ringues e, sobretudo, suas declarações e habilidade de autopromoção.

Tanto em relação ao lutador, como para a maioria das pessoas do seu entorno, o boxe é apresentado como uma forma de mudar sua condição de vida. No trabalho sobre a trajetória de Muhammad Ali, Flores (200 I, p. 35), citando Arond e Weinberg, afirma que o boxe "[...] permite aos jovens de bairros pobres terem a expectativa de um êxito rápido sem ter que recorrer a condutas desviadas". Além desta afirmação, muitos outros enunciados reforçam esta representação de que o boxe esteve articulado com a possibilidade de ascensão social dos jovens (negros, discriminados) de classes mais baixas. Essa dimensão também aparece no trabalho etnográfico de Wacquant (2002) sobre uma academia de boxe, numa comunidade afro-americana de baixa renda na cidade de Chicago. Apesar do relato de Wacquant ser de um grupo específico de boxeadores, essa representação está em acordo com o universo do boxe descrito nas narrativas em torno de Ali:

As escolas do bairro são garantia de miséria e de criminalidade. A penúria crônica de que elas precedem os prédios superpovoados e insalubres e o corpo docente subqualificado e desmoralizado são fatores que convergem para reduzí-las a instituições de guarda que se contentam estocar jovens do bairro. (WACQUANT, 2002, p. 38)

Além dessa relação do boxe com a periferia das cidades, grande parte dos documentos estudados menciona a segregação racial dos Estados Unidos na década de 1960 e 1970 como também a forte presença do cristianismo, descrevendo espaços e comportamentos e crenças "adequados" para brancos e negros em casas, restaurantes, ônibus, praças e ruas (REMNICK, 2000; MAILER, 1998; FLORES, 2001 ; MUHAMMAD ALI, 200 I; O MAIOR DE TODOS, 200 I; ALI, 2003). Estas 
obras posicionam claramente os brancos como membros dominantes e os negros numa condição de inferioridade, o que não quer dizer uma aceitação, pois muitas situações de tensão e revolta foram apresentadas. Os brancos representam, no discurso estudado, a boa sociedade (ELIAS, 200 I) ou a sociedade estabelecida (ELIAS, SCOTSON, 1994), isto é, um grupo coeso que tinha condições (poder) para definir os lugares das pessoas e os comportamentos adequados para elas. O grupo dos estabelecidos, explicam Elias e Scotson (1994, p. 7), é aquele

[...] que se autopercebe e que é reconhecido como uma boa sociedade, mais poderosa e melhor, uma identidade social construída a partir de uma combinação singular de tradição, autoridade e influência: os establisheds fundam o seu poder no fato de ser um modelo moral para os outros.

Assim, numa sociedade governada por brancos, um negro ser aceito como campeão mundial de boxe não causaria nenhum estranhamento à sociedade, já que os boxeadores profissionais eram, na sua maioria, representantes de classes sociais mais baixas e essas classes eram representadas, na sua maioria, por indivíduos negros. Eles seriam aceitos especialmente ou somente se ele se autopercebesse e fosse reconhecido de acordo com o disposto pela boa-sociedade, reforçando as normas da sociedade estabelecida.

Os afro-americanos oriundos da periferia e de classes mais baixas são constantes na representação do boxe norteamericano, em relação à carreira de Muhammad Ali. Treinados, habilidosos, fortes e motivados pela situação social, os boxeadores chamavam a atenção dos aficionados, pelo seu desempenho e pela condição social, procuravam e atraiam empresários, membros do crime organizado (máfia), políticos, agentes dos veículos de comunicação e apostadores. A respeito dessas relações oportunistas, Marqusee (2003, p. 12), afirmou que:

Desde o início o boxe foi um pote de mel para o crime. Durante o século XIX, os aristocratas britânicos foram substituídos nos EUA pelos políticos e donos de jornais, sucedidos neste século pelos magnatas de relações publicitárias, homens de negócio e donos de tevês a cabo e via satélite.

Mais do que relacionar o boxe com essas instituições, Marqusee (2003, p. 6) afirma também que foram poucas as exceções de boxeadores que não atuaram numa relação de servidão dos promotores, empresários e companhias de televisão. Porém, ao tratar da carreira de Muhammad Ali, as obras estudadas destacam menos essa ideia de dependência e mais uma dinâmica de interdependência. A interdependência entre Ali, jornalistas e apresentadores de programas de TV está bastante presente nas obras estudadas, tratando o lutador como um sujeito altamente midiático, não 
somente pelas suas habilidades esportivas, mas também pela sua postura frente a política e à cultura negra norteamericana. Em torno das "lutas", os agentes da mídia tiveram interesse em trabalhar com o boxe, em especial com Ali, pela sua capacidade de alavancar a audiência. Nas narrativas estudadas não são poucas as vezes que o lutador está em contato com agentes das empresas de comunicação 5 .

O boxe norteamericano, pela sua capacidade de atrair um público (tele) espectador e de movimentar o ramo das apostas, também é narrado a partir das relações entre os boxeadores e as pessoas do seu entorno, como empresários e membros da máfia. Os enunciados dão conta de que os desafios de pesos pesados rendiam milhões de dólares aos lutadores e empresários, mas também expõem os esquemas das "lutas arranjadas", nos quais os lutadores se submetiam aos interesses dos empresários, não raro, de indivíduos pertencentes à máfia6 .

Esse levantamento das relações sociais entre agentes e instituições retrata uma configuração que enfatiza o lutador negro, oriundo das classes mais baixas e da periferia das cidades, numa situação desfavorável, inferior diante de uma classe de agentes estabelecidos (os brancos, cristãos e suas normas institucionalizadas em governos, as empresas de comunicação, promotores-empresários e membros do crime organizado em busca de oportunidades). Nessa configuração do mundo do boxe representado, os lutadores, aceitando as determinações, tornavam-se membros da sociedade estabelecida e, ao negá-las ou resistir a elas, tendem a ser considerados o que Elias e Scotson ( 1994) denominaram de outsiders, isto é, os não membros da boa sociedade, os que estão fora dela, como um grupo heterogêneo e difuso (ou um não-grupo), marcado por laços sociais menos intensos do que aqueles que unem a sociedade estabelecida.

A narrativa a respeito da trajetória do lutador Muhammad Ali está repleta de enunciados que tratam de dizer sobre a força dos estabelecidos do mundo do boxe e de como eles tinham poder para colocar os lutadores numa condição de dependência. Contudo, a situação de Ali é descrita como diferente (e por isso, digna de ser escrita, filmada, documentada, reportada e relembrada), pois todas as fontes estudadas valorizam justamente a condição do boxeador como um outsider, ou seja, aquele que, além de resistir firmemente os adversários no ringue, em lutas extenuantes, suportou também às imposições da sociedade estabelecida. Sobressair diante das ameaças de cancelamento das lutas pelo seu vínculo com radicais islâmicos

5. Um exemplo é o momento em que Ali recorre a um apresentador de um programa de TV para conseguir agendar uma luta pela disputa do título e, assim, provocar e motivar o adversário (ALI, 2003).

6. Remnick (2000) afirma que até a década de 1960 a relação entre boxeadores e a máfia estava presente. 
e das ameaças de término da carreira no auge em virtude da sua negação de lutar na guerra do Vietnã, por exemplo, são elementos que articulam a figura do lutador como um ícone da coesão de um grupo de pessoas não estabelecidas - os negros, os manifestantes contra a guerra.

Os trabalhos que procuraram descrever a carreira de Ali, sobretudo os livros biográficos e os documentários, tratam de valorizar como Ali desvincula (não sem tensões) sua carreira da ideia de dependência da sociedade estabelecida e, cada vez mais, a desenvolve a partir da ideia de interdependência. As fontes analisadas constantemente mostram que o lutador: dependia dos veículos de comunicação para promover suas lutas, mas que estes também precisavam dele (e sua capacidade de atrair o público) para galgar maiores índices de audiência; dependia dos empresários e promotores de lutas a fim de obter lucros, mas que estes também precisavam de suas habilidades e estilo de lutar (voar como uma borboleta; picar como uma abelha) e de falar (para provocar e humilhar os adversários, jornalistas e políticos, para prever e acertar os rounds em que nocautearia os oponentes, para se promover como o lutador mais bonito, mais jovem, mais rápido, mais inteligente, o maior de todos), para alavancar os valores dos contratos, das apostas e dos rendimentos; dependia do governo, que tinha poder sobre os dirigentes das Associações de Boxe dos Estados, mas que o governo também reconhecia que o lutador tinha conquistado um papel de liderança que não poderia ser menosprezado; dependia da relação com a nação muçulmana afro-americana, o islã, para reafirmar sua postura de liberdade da escravidão, como também os líderes religiosos precisavam do lutador para agregar fiéis e dinheiro.

Essa representação da carreira do boxeador, desvinculando da dependência e valorizando a interdependência, se diferencia da trajetória de Mozart ${ }^{7}$, descrita por Elias (1995) a partir de suas noções de configuração e interdependência. Ao analisar a vida de Mozart, Elias descreve, entre outros aspectos, a passagem do músico da condição de arte de artesão ${ }^{8}$ para a arte de artista ${ }^{9}$. No decorrer do

7. Na obra Mozart: sociologia de um gênio, Elias (1995) descreveu que o músico foi considerado um outsider por romper com a hierarquia da sociedade da época (segunda metade do século XVIII), rejeitando as imposições da sociedade aristocrática. "A posição de músico nessa sociedade era basicamente a de serviçal ou a de artesão" (ELIAS, 1995, p. 124) e, numa decisão então inusitada, Mozart "pediu demissão" de seu posto na corte de Salzburgo e se estabeleceu como uma espécie de artista autônomo em Viena. Enfrentou a sociedade ao produzir músicas e óperas fora dos padrões de sua época. "Como qualquer 'gênio', Mozart era um desvio da norma em sua sociedade, uma anomalia com senso de justiça um tanto inflamável" (ELIAS, 1995, p. 120).

8. Oficial nas cortes, produzida para um patrono com status social superior ao do produtor que é subordinado, com forte caráter social e fraco caráter individual.

9. Arte criada para um mercado mais amplo de compradores, com mudança na relação de poder em favor do produtor, que podem induzir o público quanto ao seu talento - individualização do padrão. Maior independência dos artistas a respeito do gosto da sociedade, paridade social entre o artista e o comprador. 
livro, Elias preocupa-se em mostrar as relações sociais e a dinâmica de dependência que se vincularam com essa passagem e como ela não representou o sucesso do compositor, pelo contrário, determinou solidão e isolamento psicológico crescente, pois as pessoas conhecidas e seus alunos passam a abandoná-lo, seus concertos fracassam e suas dívidas aumentam. Na configuração social da época, Mozart foi um outsider e sofreu as consequências de depender da corte, morrendo pobre, apesar dos avanços que proporcionou à música.

A respeito da carreira de Muhammad Ali, o que as fontes estudadas retratam é uma ruptura do lutador com um boxe estabelecido em vista de um boxe outsider, não no que se refere propriamente ao estilo de lutar, mas sobretudo na forma de se comportar (sobre a política racial, a religião e a guerra). Porém, diferente de Mozart, a passagem do lutador de uma condição para a outra não determinou sua ruína (apesar de tê-lo causado vários problemas e impedido de lutar por vários anos), já que, Ali consegue obter muitos lucros financeiros e simbólicos nessa configuração, sendo representado como um ícone da sociedade norteamericana. Esta condição do lutador gerou duas questões que serão abordadas a seguir: em que sentido Ali pode ser considerado um outsider? Como os livros, filmes, documentários e artigos abordaram esta questão ao retratar a carreira do lutador?

\section{ALI: UM OUTSIDER?}

Após a apresentação desse olhar configuracional sobre o boxe norteamericano e a trajetória de Muhammad Ali em vista das principais relações que são enunciadas nos discursos sobre o lutador, passamos a analisar sua carreira profissional a partir de três rupturas e resistências do boxeador em relação à sociedade estabelecida (o racismo, a religião e o patriotismo), estas amplamente presentes nas narrativas a cerca de sua trajetória.

\section{ALI E O RACISMO}

A questão do racismo sempre foi muito forte na vida de Cassius Clay, sobretudo quando ainda morava em cidade Loisville, Estado de Kentucky. Este era um Estado segregacionista e até 1968 essa prática era protegida por lei (FLORES, 200 I ). Clay cresceu em meio a esta segregação, mas nunca se conformou com essa situação em que se sentia subordinado e humilhado pela maioria branca. $\bigcirc$ filme (ALI, 2003) e os documentários (MUHAMMAD ALI, 200 I ; O MAIOR DE TODOS, 200 I) analisados iniciam suas narrativas com situações nas quais Clay sentiu-se desconfortável na sua cidade natal, inferiorizado pelos brancos. E, na medida em que o lutador consegue vencer as lutas e conquistar títulos, ele adquire também maior condição para expor publicamente sua discordância à política racial. 
A sua performance está bastante vinculada às suas falas de impacto a respeito do adversário e de seu desconforto frente à política racial. No começo eram discursos que não mexiam na estabilidade social, não abalavam o que estava estabelecido, pois gritava sobre "ser o mais rápido", "o mais jovem", "o mais bonito", mas logo se percebe que estas manifestações que se davam no âmbito do boxe, se referiam a sua postura de contestação da situação racial. Uma dessas manifestações foi transcrita por Remnick (2000, p. 59): "Se eu não soubesse gritar e uivar como iria fazer para o meu público me notar? Eu ainda seria pobre. Estaria na minha cidade lavando janelas, dizendo 'sim senhor' e 'não senhor', sabendo qual é o meu lugar." Além dessa, em várias situações, mostra-se a negação de Clay em aceitar a discriminação racial e seu uso do reconhecimento e das oportunidades midiáticas para levantar questões que ultrapassavam os limites dos ringues. Quanto ao racismo se pronunciou: "Onde está o governo do negro? Onde estão seu rei e seu reino? Onde estão seu presidente, seu país, seu embaixador, seus exércitos, sua marinha e seus estadistas?" (REMNICK, 2000, p. 125).

Na configuração do boxe mostrada, Ali denota uma autopercepção bastante segura do seu desempenho nos ringues e, correspondente a isso, da sua representatividade social. A sua destreza nos ringues, sua facilidade de autopromoção, seus discursos sobre as lutas the deram uma visibilidade nunca antes alcançada no universo pugilíitico. Ele se denominava "o campeão do povo, mas não como Joe Louis” (ALI, 2003), este que várias vezes é mencionado, por Ali, num sentido depreciativo, por ele ser representante de uma sociedade estabelecida, numa carreira permeada por normas determinadas numa cartilha ${ }^{10}$, às quais deveria se enquadrar: nunca deveria ser fotografado ao lado de uma mulher branca; nunca deveria ir à boate, desacompanhado; nunca deveria debochar de um oponente; e nunca deveria debochar de um oponente caído. Enfim, deveria manter uma imagem pacata frente às câmeras (FLORES, 200I).

Joe Loius foi campeão de boxe nas décadas de 1930 e |490. Sua aceitação social era enorme e um dos motivos foi sua vitória contra Max Schmelling, um alemão que servia como propaganda ao partido nazista na era Hitler (FLORES, 200 I). Esta luta como boa figuração diante dos anseios da sociedade americana, teve um caráter racista muito forte, pois o partido nazista queria provar a soberania da raça ariana sobre a raça negra e após uma primeira derrota para o lutador alemão, Louis o derrotou numa revanche no primeiro round. Diferente de Loius, Muhammad Ali

10. Essa cartilha era feita por um grupo de empresários que administravam a carreira de Louis e transformaram o lutador no representante ideal de sua raça (bom negro), pois servia à sociedade como um reforço às suas normas. 
assume uma postura de enfrentamento à sociedade estabelecida norteamericana, fortemente vinculado à discriminação racial interna. Suas declarações não se limitavam a promover suas lutas, serviam simultaneamente para questionar normas e padrões sociais vigentes, tendo como respaldo sua performance atlética e reconhecimento no cenário do boxe.

\section{ALI E A RELIGIÃO}

Outra ruptura de Cassius Clay com a sociedade estabelecida esteve vinculada a questão religiosa. Em 6 de março de 1964 ele se converte ao islamismo e muda seu nome para Muhammad Ali, nome que ficaria conhecido mundialmente. A mudança do nome teve um significado social muito importante, pois, com essa atitude, nega seu nome de batismo e passa a negar a religião cristã e sua prática: "não rezo mais para o Jesus loiro" (ALI, 2003). Além de se declarar a favor de uma prática diferente da convencional, passa a divulgar as ideias dos muçulmanos negros, negando o Deus cristão e defendendo as idéias de Alá (FLORES, 200 I). Esta decisão está diretamente ligada à questão racial, uma vez que a vertente islâmica escolhida por Ali se diferencia da visão tradicional muçulmana - era "a religião da independência negra" (O MAIOR DE TODOS, 200I).

Os discursos a respeito desse vínculo com a nação muçulmana têm uma conotação de liberdade do boxeador da condição de escravo. "Cassius Clay é meu nome de escravo, já não escravo", diz o lutador quando um repórter lhe pergunta o motivo da mudança de nome (MUHAMMAD ALI, 200I). Face a essa ruptura com o cristianismo, são trazidos alguns eventos que marcaram repreensões, especialmente pelo vínculo com um dos representantes mais extremistas, que pregava contra os demônios brancos (Malcom X). Duas delas estão no documentário $\bigcirc$ Maior de Todos (200 I): uma quando o próprio treinador questiona a relação com Malcom X e ouve de Ali a seguinte resposta: "Cuide do boxe que eu cuido da religião"; e a outra é feita pelo empresário que ameaça cancelar a luta pelo título mundial, situação que foi enfrentada por Ali com resistência, fazendo o promotor voltar atrás e manter o contrato.

No jogo das relações dentro das configurações, a mudança do nome representou ganhos tanto para o lutador como para a religião. Como explicou Mailer ( 1998) o grupo religioso só dava nomes muçulmanos para frequentadores antigos da religião e Ali mudou seu nome logo depois de se converter. Essa mudança representou um interesse em utilizar a imagem de Ali em benefício próprio: tendo um campeão mundial ligado à sua religião esse grupo se fortalecia socialmente, pois Ali representava uma forte propaganda para divulgação das suas ideias. É retratada uma relação mútua de 
interesse (interdependência) no vínculo de Ali com os muçulmanos negros: enquanto Ali se utilizava das ideias desse grupo fortalecer seus questionamentos relacionados à religião e ao racismo, os muçulmanos negros utilizavam a figura de Ali como um esportista que estava na mídia e tinha uma grande representatividade social para fortalecer suas ideias e conquistar mais adeptos.

Muhammad Ali, pelas suas manifestações de desconforto com a política racial e sua conversão ao islamismo, é representado numa condição de inspirador da coesão social de um grupo outsider, alguém que ensinou à população que ser negro não é ser inferior, que ser negro não é ser feio - "levou os negros a pensarem que eram bons, não, que eram os melhores" (MUHAMMAD ALI, 200I). Mas, alguns relatos indicam que esta não se tratava, necessariamente, de um comportamento auto-iniciado, mas sim de orientações dos líderes religiosos. Um dos depoimentos do documentário intitulado Muhammad Ali (200 I) denota que "Ali não agia espontaneamente, foi orientado pelos muçulmanos, parecia quase um robô, ia aos locais onde Ihe mandavam ir, dizia o que as pessoas Ihe pediam". Quer dizer, o lutador que se vinculou à religião para se libertar dos estabelecidos acaba por atender outras agendas que não a da boa sociedade.

\section{ALI E A GUERRA DO VIETNÃ}

Ali não apenas deixou de apoiar, como se mostrou contra um fato histórico marcante da sociedade americana: a guerra do Vietnã. Precisando de mais soldados para lutar no Vietnã, o exército convocou o boxeador, mas este se negou a participar da guerra, alegando motivos raciais e religiosos.

Por que me pedem que vista uma farda e vá para um local a 15 mil km de casa, atirar
balas e bombas no povo pardo do Vietnã, enquanto os chamados negros de Louisville
são tratados como cães e lhes negam os direitos humanos? Não, eu não vou para um
local a I 5 mil km de distância para ajudar a matar e queimar outra pobre nação, só para
continuar com o domínio de senhores brancos de escravos sobre pessoas mais escuras
do mundo. Chegou o dia em que tais maldades têm de acabar. (trecho da fala do lutador,
lido no documentário MUHAMMAD ALI, 200 I)

A convocação de Ali para o exército, tal como enfatizam as narrativas, não tinham o propósito de colocá-lo nas trincheiras, mas de estabelecer relações com campeão mundial de boxe, em defesa de uma ideia que deveria ser aceita pela sociedade. Quando ele comparece nas forças armadas para o alistamento e se nega a fazer parte do exército, um oficial é mostrado tentando convencê-lo a aceitar a convocação, dizendo que "você não vai receber um rifle", da mesma forma que fez o Sargento Joe Louis, que fez exibições na Segunda Guerra Mundial (O MAIOR 
DE TODOS, 200 I). Ele poderia ter feito parte do exército disputando lutas amistosas e nunca teria que ir para as trincheiras ou algo parecido (MUHAMMAD ALI, 200 I). Mais uma vez, Joe Louis é utilizado, nas narrativas para marcar a posição de Ali e este reafirma sua diferença, rompendo com o papel de bom negro, membro da boa sociedade.

Alegando que "eles [os vietcongs] nunca me chamaram de negro" (ZERO HORA, 2000b, p. 5I), por isso, não teria motivos para lutar nessa guerra, Ali mantém-se firme em sua decisão e é condenado a cinco anos de prisão. Após pagamento de fiança, ficou aguardando os julgamentos de recursos em liberdade, mas sem poder lutar nos Estados Unidos ou viajar para fora do país. As consequências deste posicionamento não foram pequenas. Após ela, Ali é mostrado com dificuldades financeiras, tornou-se um esportista odiado em vista de sua negação ao patriotismo" e também teve seu título de campeão do mundo retirado, assim como sua licença para lutar'2.

Conforme isso é narrado, o boxeador sabia das consequências e as assumiu, como se abandonasse o título em prol de seus princípios vinculados à raça e à religião. A respeito disso, Flores (200I, p. 69) transcreve a seguinte afirmação do lutador: "Eu vou lutar legalmente [nos tribunais]. Se perder vou para a prisão. Não vou trair a religião do Islã" (FLORES, 200 I , p.69). Nesta situação, Ali passou por três anos de dificuldades financeiras, mas, por fim, é absolvido pela Suprema Corte, que aceitou sua alegação de que "sendo sacerdote dos muçulmanos, estava dispensado do recrutamento" (MUHAMMAD ALI, 200 I).

Por fim, em 1970, o apoio à guerra ia perdendo força e se estabelecia uma pressão social por parte de artistas e personalidades com relevância social (FLORES, 200 I ) pela volta do boxeador aos ringues. Assim, Ali volta a lutar, e, em 1974, recupera seu título mundial contra Jorge Foreman, numa luta realizada no Zaire, considerada a luta do século. Em 1978, vence Ken Norton e ganha o título de campeão mundial mais uma vez, tornado-se o primeiro tri campeão mundial de boxe peso pesado. Em junho de 1979 se retira dos ringues. Anos depois foi reconhecido como o maior lutador de todos os tempos. Nas olimpíadas de Atlanta em 1996 acendeu a pira olímpica na festa de abertura (ZERO HORA, 2000a, p. 54). Em 199I, Ali ajuda no resgate de 15 soldados americanos na guerra do Golfo.

Estas participações como representante da sociedade americana - como um estabelecido - foram possíveis por conta de uma complexa conjuntura de

I I. Tema caro à sociedade norteamericana.

12. As Associações de Boxe dos Estados eram vinculadas ao Governo, que tentava diminuir a representatividade do boxeador impedindo-o de lutar. 
interdependências desenvolvida pelo lutador no boxe e na religião e da mudança da estrutura da sociedade. Nos dias de hoje, Ali sofre do mal de Parkinson, resultado dos inúmeros socos que levou durante a sua carreira. Mesmo assim, utilizando sua representatividade social, sua imagem de melhor atleta de luta de todos os tempos para trabalhar em obras assistenciais que tratam de pacientes que sofrem dessa doença (ZERO HORA, 2000c, p. I5)

\section{CONCLUSÃO}

Muhammad Ali teve uma representatividade social lutando contra os padrões de sua época. Conquistou esse status em uma sociedade com padrões morais rígidos e normas estipuladas por um grupo social coeso que controlavam a figuração do boxeador para reforçar crenças antigas. De certa forma Ali compreendeu que o poder é um atributo das relações entre agentes e não somente uma substância de um agente. $\bigcirc$ seu elevado talento para o boxe foi um dos fatores que fez com que tivesse sucesso na sua carreira profissional, mas, para além disso, o lutador reformulou sua rede de relações e interdependências com grupos também dominados/ estigmatizados pela sociedade americana.

Por isso, ainda que estabelecido dentro do grupo de boxeadores, Ali se opôs a algumas determinações sociais, morais vinculadas ao contexto mais amplo da sociedade americana. A análise de sua posição em relação ao racismo, a religião e a guerra do Vietnã, tornou possível compreender que Ali foi também um outsider. Mas, se de um lado, Ali tornou-se um outsider a partir de três questões fundamentais para a sociedade da época, por outro, foi um lutador que gerava muito dinheiro e publicidade para os envolvidos com o esporte, jogando o jogo dos estabelecidos. As relações sociais de Ali estiveram simultaneamente vinculadas a grupos estabelecidos e grupos outsiders. O lutador vivia em uma época em que a estrutura social era complexa e as questões de comportamento social na esfera do boxe estavam relacionadas com os outros interesses, daí a impossibilidade de distanciamento do grupo estabelecido.

Esse contexto implica em mais uma diferença entre as carreiras de Muhammad Ali e de Mozart. Mesmo sendo um talento para a música, como era o caso de Mozart, ele não conseguiu ter sucesso na sua carreira e foi reconhecido apenas após sua morte como um dos "gênios" da música. Assim como Ali, Mozart estava subordinado a uma estrutura social em que um grupo mais coeso ditava as normas a serem seguidas de acordo com os interesses desse grupo dominante. Mozart também se negou a esse papel não aceitando as condições impostas por esse grupo, mas morreu com dificuldades financeiras e só foi reconhecido como músico de talento após sua morte (ELIAS, 1995). 
Ali vivia em uma sociedade diferente de Mozart, em que ele também estava subordinado a um grupo dominante, um grupo que estabelecia que um campeão mundial de pesos pesados devesse ser um exemplo para a sociedade, deveria ser um bom negro ou, pelo menos, se omitir quando contrário fosse a questões sociais importantes. Além disso, deveria ser cristão e - por patriotismo - apoiar a guerra do Vietnã; como foi demonstrado, ele não aderiu a nenhuma dessas formas de pensamento e se posicionou contrariamente a elas. Porém, o boxeador tinha duas características que se adequavam muito bem à estrutura social que envolvia o esporte que praticava: um talento acima da média e uma alta capacidade de autopromoção. E, diferente de Mozart, cujo aptidão não era valorizada pela corte, essa característica esportiva era muito estimada na sociedade americana da época de Ali. Como substância, essas qualidades não determinariam um poder, mas nas relações com outros agentes e grupos, elas formaram uma configuração favorável ao boxeador.

O talento (aqui entendido como segunda natureza) para a atividade de boxeador (para Ali) e de músico (para Mozart) tem o mesmo significado. Ambos foram considerados talentosos nas suas sociedades. A diferença é que, na sociedade de Mozart, os outsiders eram subordinados aos estabelecidos, estes últimos os únicos responsáveis por ditar as normas e determinar o que era "bom para a sociedade", impedindo outros arranjos de relações em torno desse talento: apesar de ter se distanciado da corte e de ter buscado trabalhar na cidade, a demanda pela sua música era dos cortesãos em ambos os espaços. No caso de Ali, o fato de viver numa sociedade em que distintos grupos reconheciam seu talento, tornou possível estabelecer arranjos de relações mais favoráveis, que lhe permitiram experiências em desacordo com a sociedade estabelecida. Elias (2005) indica diferenças desse tipo de vínculo entre a configuração social e ação individual ao relatar o caso de Beethoven, que, tendo nascido I 5 anos mais tarde que Mozart, conseguiu liberar-se da dependência do patronato, pois - num contexto configuracional mais complexo - teve mais oportunidades para impor o seu gosto ao público musical.

Outra característica fundamental para o sucesso da carreira de Ali foi a sua capacidade de autopromoção, que foi crucial nas relações de poder do boxe. Ali tinha um talento fora do ringue para promover suas lutas e gerar notícias nunca antes vistas nesse esporte. Sabia que isso era essencial para seu sucesso e tinha uma relação forte com a imprensa. As poesias que fazia para seus adversários, seus comentários sobre o round em que seu oponente iria ser derrotado e seu jeito extrovertido de lidar com a mídia renderam a esse atleta um índice de popularidade poucas vezes alcançado por um atleta. Era muito difícil calar um atleta que continuava ganhando suas lutas e se promovendo da maneira que Ali fazia. 
A tentativa de um grupo de estigmatizar Ali, destacando-o como sujeito afastado dos padrões sociais estabelecidos, não foi suficiente. A configuração das relações de poder desenvolvidas em torno desse (ou por esse) lutador lhe deixou em situação favorável para dizer o que pensava e, ainda assim, continuar a lutar e ser campeão. Assim, ele acaba sendo reconhecido como ícone da sociedade norteamericana, tendo representado seu país em um dos mais importantes eventos esportivos e no salvamento de soldados na guerra do Golfo.

Significa dizer que, se por um lado Ali pode ser considerado um outsider por enfrentar padrões sociais, por outro pode ser considerado um estabelecido por saber jogar o jogo do mundo do boxe, que vai bem além dos treinos e das lutas. Tal constatação permite alertar para o fato de que a aplicação rígida da teoria dos estabelecidos e outsiders revela uma divisão maior ou mais forte do que a percebida no caso do Ali, este, que, simultaneamene, participou dos dois grupos. Portanto, ao fazer relação com o que foi escrito no presente artigo e no intuito de que novos estudos se debrucem sobre o tema em questão, duas perguntas podem ser feitas: numa sociedade como a vivenciada pelo lutador, Muhammad Ali foi um outsider na sociedade americana? E, além disso, até que ponto é possível a aplicação rígida da teoria de Elias em sociedades com outras dinâmicas de funcionamento?

\section{Muhammad Ali, an Outsider in American Society?}

ABSTRACT: The study analyses the career of the boxer Muhammad Ali according to the formulations on power relations in configurations presented by Norbert Elias. The aim was to understand how an athlete that was against such deep matters of the established society achieved professional success. It is a documental study, with sources such as books, articles and newspaper reports about the boxer's life. The conclusion is that despite the fact that the boxer opposed established patterns for the time in issues such as religion, racism and patriotism, his above average skill, his self-promotion power and his ability to participate of the game in the configurational context in which he was inserted gave him survival conditions in the boxing world and consequent professional success.

KEYWORDS: Muhammad Ali; boxing; configurations.

\section{Muhammad Ali, un outsider en la sociedad americana?}

RESUMEN: El estudio analiza la carrera del boxeador Muhammad Ali según las formulaciones sobre las relaciones de poder en configuraciones presentadas por Norbert Elias. El propósito fue comprender como un atleta que fue contra cuestiones tan profundas de la sociedad establecida obtuvo suceso profesional. Se trató de un estudio documental, teniendo como fuente libros, artículos y reportajes publicados sobre la trayectoria del luchador. Se concluye que a pesar de Ali haberse posicionado contra padrones establecidos de su época 
en cuestiones como la religión, el racismo y el patriotismo, su habilidad técnica arriba de la media, su poder de auto promoción y su capacidad de participar del juego en el contexto configuracional del que hacia parte, le dieron condiciones de sobre vivencia en el mundo del boxeo y consecuente suceso profesional.

PALABRAS CLAVE: Muhammad Ali; boxeo; configuraciones.

\section{REFERÊNCIAS}

ALI. A verdadeira história de Muhammad Ali. Filme. Produção de Peters Entertainment/Forward Pass em sociedade com Lee/Caplin/Picture Entertainment Corporation e Overbrook Films. Direção de Michal Mann. Manaus: Videolar, sob licença da Initial Entertainment Group e Columbia Pictures, 2003. I DVD (I 57 min.): Digital, color., dublado. Português.

ELIAS, N. O processo civilizador. Rio de Janeiro: Jorge Zahar, 1994.

Mozart: sociologia de um gênio. Rio de Janeiro: Jorge Zahar, 1995.

A sociedade de corte: investigação sobre a sociologia da realeza e da aristocracia de corte. Rio de Janeiro: Jorge Zahar, 200 I. Introdução à sociologia. Lisboa: Edições 70, 2005.

ELIAS, N; SCOTSON, J. L. Os estabelecidos e os outsiders: sociologia das relações de poder a partir de uma pequena sociedade. Rio de Janeiro: Jorge Zahar, 2000.

FLICK, U. Introdução à pesquisa qualitativa. 2. ed. Porto Alegre: Bookman, 2004.

FLORES, J. E. Jr. A luta além dos ringues: a emocionante trajetória de Muhammad Ali. Porto Alegre: Sagra Luzzato, 2001.

MAILER, N. A luta. São Paulo: Companhia das Letras, 1998.

MARQUSEE, M. Sport and stereotype: from role model to Muhammad Ali. Race Class. v. 36, n. 4, p. I-29, abr. 2003.

MUHAMMAD ALI. Aos olhos do mundo. Documentário. Produção de Phil Grabsky e Louise Murray. Documentário. Direção de Phil Grabsky. Manaus: Microservice Tecnologia Digital da Amazônia, sob licença da Universal Pictures Internacional BV, 200 I. I DVD (I09 min.): Digital, Color., Legendado. Português.

O MAIOR DE TODOS. A história de uma lenda que varreu todo o mundo. Documentário. Produção de John Marshall, Ernest Borgnine, John Marley e Lloyd Haynes. Direção de Tom Gries. Manaus: Videolar, sob licença de Columbia TriStar Home Entertainment do Brasil, 200 I. I DVD (I0I min.): Digital, Color., inglês, legendado. Português. 
REMINICK, D. O rei do mundo: Muhammad Ali e a ascensão de um herói americano. São Paulo: Companhia das letras, 2000.

WACQUANT, L. J. D. Corpo e alma: notas etnográficas de um aprendiz de boxe. Rio de Janeiro: Relume Dumará, 2002.

ZERO HORA. Atletas do século. Zero Hora, Porto Alegre, 30 ago. 1998, p. 58.

ZERO HORA. Cassius Clay bate forte com os punhos e com as palavras. Zero Hora, Porto Alegre, p. 54. 01 ago. 2000a.

ZERO HORA. Nos 50 anos de Ali saudades dos bons tempos. Zero Hora, Porto Alegre, p. 54, 0 I de ago. 2000b.

ZERO HORA. Muhammad Ali. Zero Hora, Porto Alegre, 17 ago. 2000c, p. 15.

Recebido: 14 set. 2009

Aprovado: 18 ago. 2010

Endereço para correspondência:

Marco Paulo Stigger

Rua Afonso Taunay, 193, apt. 802 - Bairro Boa Vista

Porto alegre - RS

CEP: $90.520-540$ 